Meta

Journal des traducteurs

Translators' Journal

\title{
El trasvase de la voz en el doblaje de Cyrano de Bergerac
}

\section{Ana Mallo}

Volume 60, numéro 2, août 2015

$60^{\mathrm{e}}$ anniversaire. Les horizons de la traduction : retour vers le futur

$60^{\text {th }}$ Anniversary. Translation's Horizons: Back to the Future

60mo aniversario. Los horizontes de la traducción: regreso al futuro

URI : https://id.erudit.org/iderudit/1032906ar

DOI : https://doi.org/10.7202/1032906ar

Aller au sommaire du numéro

Éditeur(s)

Les Presses de l’Université de Montréal

ISSN

0026-0452 (imprimé)

1492-1421 (numérique)

Découvrir la revue

Citer ce document

Mallo, A. (2015). El trasvase de la voz en el doblaje de Cyrano de Bergerac. Meta, 60(2), 355-355. https://doi.org/10.7202/1032906ar d'utilisation que vous pouvez consulter en ligne.

https://apropos.erudit.org/fr/usagers/politique-dutilisation/ 


\title{
El trasvase de la voz en el doblaje de Cyrano de Bergerac
}

\author{
Ana Mallo \\ Universidad de Valladolid, Soria, España \\ amallo@lesp.uva.es
}

La obra teatral Cyrano de Bergerac, (París, 1897) destaca por su belleza estética: 2.570 versos dispuestos en pareados de alejandrinos alternando las rimas, según los cánones del teatro clásico y romántico francés. Además de ser una de las obras más representadas en el mundo, se ha traducido a numerosos idiomas: español, inglés, ruso, japonés, entre otras.

La primera versión cinematográfica se realizó en 1900, en cine mudo. Siguió llevándose al cine en años sucesivos. En 1990, Jean-Paul Rappeneau inmortalizó la historia a través de la gran pantalla, con Gérard Depardieu como protagonista. En la versión en español de este filme, desde el punto de vista de la Traducción Audiovisual, y en concreto en el doblaje, uno de los problemas más interesantes que se plantean es el del trasvase de la voz. Analizaremos el tratamiento dado a la voz en el cine y particularmente a la voz del protagonista Cyrano, rica en registros y matices.

Para ello es necesario poner de manifiesto el significado y cualidades de la voz y tener en cuenta su papel como vehículo para la emisión de sonidos y palabras y cómo estos sirven para comunicar, conocer y compartir emociones, sentimientos o estados de ánimo. El análisis de cómo se produce la voz desde el punto de vista fisiológico y de sus cualidades: intensidad, duración, timbre y tono, es fundamental para comprobar que, desde una perspectiva científica, dichas cualidades provocan una sensación determinada y subjetiva en el ser humano.

El hecho de conocer cómo afecta cada cualidad de la voz a la hora de transmitir diferentes emociones es de gran utilidad en el terreno cinematográfico, ya que permite al director, tanto de la película como del doblaje, seleccionar determinadas voces con la finalidad de crear en el espectador una imagen determinada y sugerir así diferentes sensaciones.

Ana $\mathrm{M}^{\mathrm{a}}$ Mallo Lapuerta es Doctora en Traducción e Interpretación por la Universidad de Valladolid. Su tesis doctoral versa sobre la traducción audiovisual y, en concreto, sobre el doblaje cinematográfico. En el año 2000 fue nombrada Traductora e Intérprete Jurado por el Ministerio de Asuntos Exteriores. Desde el año 2002 es profesora de traducción en la Facultad de Traducción e Interpretación de la Universidad de Valladolid e imparte clases de traducción audiovisual y traducción para entornos de discapacidad en el Máster Europeo Traducción Profesional e Institucional [programa de excelencia europeo y miembro de la Red EMT(European Masters in Translation) de la Comisión Europea y de la Red Académica Erasmus OPTIMALE (Optimising Professional Translation Training in a Multilingual Europe)]. Pertenece a diferentes grupos de investigación, destacando el GIR de Excelencia Traducción y Nuevas tecnologías (ITNT) en el que se elaboran proyectos como la elaboración de un diccionario multilingüe de genética. Actualmente, sus investigaciones están enfocadas en el campo de la traducción audiovisual. 